\title{
Histology and Histomorphometry of Testes in Turkeys (Meleagris gallopavo) Based on Age Level
}

\author{
Nasya Nurma Zushita Firwan ${ }^{1}$, Muslim Akmal $^{2}$, Dian Masyitha², M. Nur Salim³ , M. \\ Jalaluddin $^{4}$, Tongku Nizwan Siregar ${ }^{5}$
}

\begin{abstract}
${ }^{1}$ School of Veterinary Medicine, Faculty of Veterinary Medicine, Universitas Syiah Kuala, Banda Aceh, Indonesia ${ }^{2}$ Laboratory of Histology, Faculty of Veterinary Medicine, Universitas Syiah Kuala, Banda Aceh, Indonesia ${ }^{3}$ Laboratory of Pathology, Faculty of Veterinary Medicine, Universitas Syiah Kuala, Banda Aceh, Indonesia ${ }^{4}$ Laboratory of Anatomy, Faculty of Veterinary Medicine, Universitas Syiah Kuala, Banda Aceh, Indonesia ${ }^{5}$ Laboratory of Reproduction, Faculty of Veterinary Medicine, Universitas Syiah Kuala, Banda Aceh, Indonesia *Corresponding author.Email:nasyafirwan@gmail.com
\end{abstract}

\begin{abstract}
This study aims to determine the histological and histomorphometric features of the turkey testes based on age levels. Turkey testes were taken from 21 male turkeys which were grouped into 3 different age groups; 12, 20 and 33 weeks. The testes were then processed into histological preparations with a thickness of 3-5 $\mu \mathrm{m}$ and stained with hematoxylineosin (HE). The result showed that histological structure of the turkey testes has different characteristics in different age group. The spermatocytogenesis phase occurred at 12 weeks of age, while the myogenesis phase and the spermiogenesis phase were occurred at 20 weeks and 33 weeks, respectively. Histomorphometric data were analyzed by ANOVA which showed that there was a significant difference between seminiferous tubule diameter, seminiferous tubular epithelial thickness and seminiferous tubule lumen diameter based on age level $(\mathrm{P}<0.05)$. As conclusion, there were different spermatogenesis phases with different age group of turkeys. The development of the spermatogenesis phase at each age group of turkey increases the seminiferous tubule diameter, seminiferous tubule epithelial thickness and seminiferous tubule lumen diameter.
\end{abstract}

Keywords: Testes, age, turkey, histology, histomorphometry

\section{INTRODUCTION}

Turkey is a large type of poultry originating from America and domesticated by Indian tribes [1]. Currently, there is very little information on the reproductive system of turkeys in Indonesia. Reproduction is an important part of producing new offspring and maintaining the species from extinction. Basically, if there is no reproduction, the population of an animal will not increase [2].

The reproductive system of livestock will develop and start the reproductive process when the animal has entered the sexual maturity stage [2]. Reproductive organs play an important role in the reproductive activity of an animal species [3]. The reproductive organs of male turkeys are the same as other types of birds, they are a pair of testes, a pair of deferens that lead to the cloaca, and a copulation tool called a phallus [4]. The testes are one of the male reproductive organs that functions to produce spermatozoa, which are male sex cells that are in the lumen of the seminiferous tubules and function to fertilize the ovum [5], and produce the hormone testosterone which is a steroid hormone to help the process of spermatozoa formation [6]. The testes in poultry are located in the abdominal cavity at the front of the kidneys, at the back of the lungs, and are lined with fibrous tissue [7].

The turkey life phase consists of six phases, namely the pre-starter phase at 0-4 weeks, the starter phase at 4-8 weeks, the grower I phase at 12-16 weeks, the grower phase II at 16-20 weeks, and the finisher phase at 20 weeks. Turkeys at 33 weeks old are considered sexually mature and can be used as breeds [8].

The results of research on testicular morphology and histology in other birds have been previously reported by 
Gerzilov et al. [9]. In that study, it was found that age had an effect on changes in testicular morphology and histology. Based on this, further research was carried out regarding the histological and histomorphometric features of the turkey testes (Meleagris gallopavo) based on different age levels.

\section{MATERIALS AND METHODS}

This research was conducted at the Laboratory of Histology, Faculty of Veterinary Medicine, Syiah Kuala University, Banda Aceh. This study used testicular samples from 21 male turkeys (Meleagris gallopavo) obtained from Rumah Kalkun Mitra Alam, Sukaharjo I District, Pringsewu Regency, Lampung Province. Samples were then grouped into three age groups; 12, 20 and 33 weeks old turkeys, each of which consisted of 7 male turkeys. The sample size calculation is calculated using the Federer formula [10] as follows:

$$
\begin{aligned}
& (\mathrm{t}-1)(\mathrm{n}-1) \geq 15 \\
& (3-1)(\mathrm{n}-1) \geq 15
\end{aligned}
$$$$
2 \mathrm{n}-2 \geq 15
$$$$
2 n \geq 15-2
$$$$
2 n \geq 13
$$$$
\mathrm{n} \text { : number of }
$$$$
\text { samples }
$$$$
\mathrm{t}: \text { number of }
$$

$\mathrm{n} \geq 6.5 \sim 7$

The ideal sample size according to Federer's formula was 7 or more male turkeys. Therfore, the total number of male turkeys in all age groups was 21 .

\subsection{Collection of Turkey Testicles}

Each turkey was slaughtered and its testis was collected. The testes were rinsed with $0.9 \% \mathrm{NaCl}$ solution until clean, put into a closed container filled with $10 \%$ $\mathrm{NBF}$, and fixed for 48 hours. Each sample was labeled and then transferred to a $70 \%$ alcohol solution as a stopping point until the dehydration process was carried out.

\subsection{Preparation of Histological Samples}

The histological preparations were conducted according the Kiernan method [11]. The process was initiated with dehydration of testicular tissue using graded alcohol concentrations $(80 \%, 90 \%, 95 \%$, absolute I, and absolute II), purification with xylol solution, infiltration in liquid paraffin, and tissue embedding in paraffin, followed by blocking, sectioning with an incision thickness of 3-5 $\mu \mathrm{m}$. The results of the incision were stained with hematoxylin-eosin (HE) staining.

\subsection{Hematoxylin-Eosin Staining}

The samples were deparaffinized using xylene, rehydrated in a decreasing ethanol series, and rinsed with running water. The tissue slides were then put in hematoxylin for 5 minutes and eosin for 5 minutes, then the dehydration process was carried out using ethanol (96\% ethanol I and II, absolute I and II, dipped twice each). After that, the clearing process was carried out with Xylene I, II, III for 3 minutes each, then mounted with Entellan ${ }^{\circledR}$ [11]. Observations were made with an Olympus CX31 light microscope.

\subsection{Observation of The Histological and Histomorphometric Features of the Turkey Testes}

Histological observations included spermatogenic cells features consisting of spermatogonia, primary spermatocytes, secondary spermatocytes, spermatids, spermatozoa as well as Sertoli cells and Leydig cells. The histomorphometric observations of the turkey testes included the thickness of the seminiferous epithelial layer which was measured from the membrane to the lumen boundary, the seminiferous tubule diameter, and the seminiferous tubule lumen diameter. The measurement used a toupview application program which is then connected to the Olympus CX31 microscope using a sigma camera connected to a computer, after connecting with the application, a straight line is drawn in red with a line drawing angle of $90^{\circ}$. The seminiferous tubules that were chosen to be measured were the seminiferous tubules which were round as many as 10 tubules.

\subsection{Data Analysis}

The histological features of turkey testes were analyzed descriptively while histomorphometric data were analyzed using ANOVA (Analysis of Variance).

\section{RESULTS AND DISCUSSION}

\subsection{Turkey Testicular Histology}

The results of histological observations of turkey testes based on age levels showed that the histological structure of the turkey testis was the same as other animal species consisting of spermatogenic cells including spermatogonia, primary spermatocytes, spermatids, spermatozoa and Sertoli cells in the germinal epithelial layer and Leydig cells in the interstitial tissue. These spermatogenic cells differentiate from spermatogonia to become spermatozoa cells according to the age of the turkey. According to Eroschenko [12], the seminiferous tubule is part of the testis in the form of a round and tortuous reed consisting of germinal epithelium or spermatogenic cells and Sertoli cells and is a place for 
differentiation of germ cells, from spermatogonia cells to spermatozoa cells [13].

Spermatogenesis process is divided into three phases: spermatocytogenesis, myogenesis, and differentiate ohase. Spermatocytogenesis phase starting with spermatogonia which consists of type A with a pale color and type B with a dark color. Type A spermatogonia divides into type B spermatogonia which then proliferates mitosis to produce primary spermatocytes. In myogenesis phase, haploid spermatids are produced. Primary spermatocytes divide to produce secondary spermatocytes. Secondary spermatocytes divide to produce round spermatids. In the meiosis process, the number of chromosomes and DNA in each cell will decrease. Differentiation phase, this phase is also called the spermiogenesis phase, in which round spermatids that have been formed, differentiate into elongated spermatids which have flagella to move and mitochondria to produce energy.

\subsection{A 12-Week Old Turkey Testicule}

Testes turkey of 12 weeks age is shown in Figure 1. Figure 1 showed that the number of seminiferous tubules was still small and the seminiferous tubules look empty and there is no activity of spermatogenic cells. The seminiferous tubules in 12 weeks of age turkey also showed the presence of spermatogonia, Sertoli cells, and Leydig cells located in the interstitial tissue of the seminiferous tubules. Spermatogonia cells in the seminiferous tubules appear to be more dominant than other cells. Vazquez et al. [14] stated that spermatogonia are the largest germ cells in the testes, round or oval in shape and located one layer below the basement membrane consisting of two types, namely type A spermatogonia with a pale color and type B spermatogonia with a darker color [15].

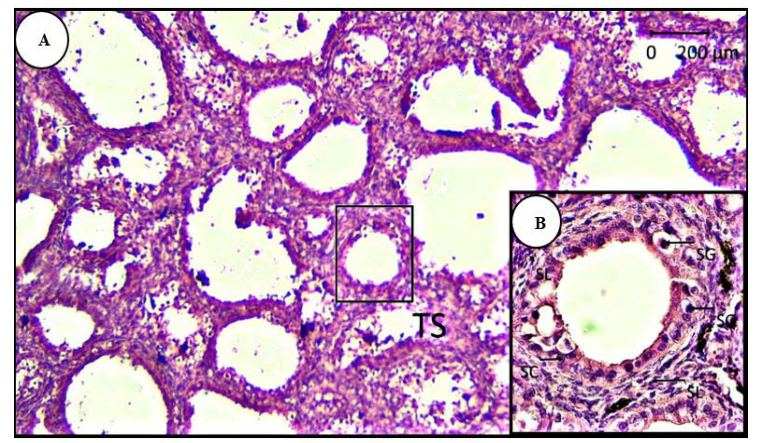

Figure 1 A 12-week old turkey testicular microphotography. (A). The number of seminiferous tubules is still small. Seminiferous tubule (TS) is not filled with spermatogenic cells and the lumen is still empty. (B). Inset $A$, showing the presence of Spermatogonia (SG); and Sertoli cells (SC) in the germinal epithelium and Leydig cells (SL) in the interstitial tissue. HE staining. Scale: $200 \mu \mathrm{m}(\mathrm{A})$ and $30 \mu \mathrm{m}(\mathrm{B})$.
Sertoli cells are testicular support cells located between germ cells in the seminiferous tubules [16] which provide physical support and provide nutrition for spermatid development [17].

According to Mruk and Cheng [18], the function of Sertoli cells is influenced by Follicle Stimulating Hormone (FSH) which facilitates the spermatogenesis process, while Leydig cells function to secrete androgen hormones and regulate the spermatogenesis process [19].

\subsection{A 20-Week Old Turkey Testicle}

The histology of 20 old weeks turkey testis is presented in Figure 2. Figure 2. showed the presence of spermatogonia, primary spermatocytes, Sertoli cells, and Leydig cells in equal numbers, while secondary spermatocytes immediately divide into round spermatids so that their presence is rarely seen. Spermatids round were seen in large numbers and some of them had transformed into elongated spermatids, and there were also spermatids which indicated that the 20 weeks old turkey testes were reaching maturity. Aire [20] states that the development of the testes is marked by the presence of large numbers of spermatocytes in the seminiferous tubules, the spermatids have appeared to have spread and the process of spermatozoa formation has begun.

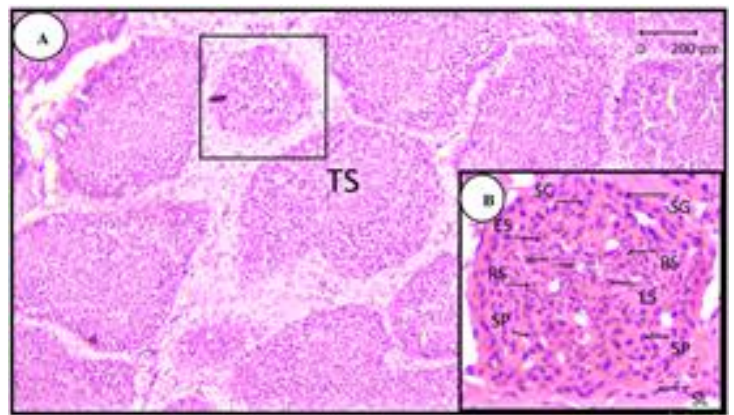

Figure 2 A 20-weeks turkey testicular microphotography. (A). The number of seminiferous tubules has started a lot. The Seminiferous Tubule (TS) is filled with spermatogenic cells. (B). Inset A, showing the presence of Leydig cells (SL) in the interstitial tissue; Sertoli cells (SC); Spermatogonia (SG); Primary Spermatocytes (SP); Round Spermatid (RS); Elongated Spermatid (ES); and a little Spermatozoa (Sperm). HE staining. Scale: $200 \mu \mathrm{m}$ (A) and $30 \mu \mathrm{m}(\mathrm{B})$.

\subsection{A 33-Week Old Turkey Testicle}

The 33-weeks old turkey testes are shown in Figure 3. The figure showed the presence of spermatogonia and primary spermatocytes. The seminiferous tubules in 33 weeks of age turkey also showed round spermatids and elongated spermatids which had been transformed into perfect and mature spermatozoa cells. According to Dreef et al. [21], secondary spermatocytes are rarely seen on histological observations due to the rapid differentiation of secondary spermatocytes into round spermatids. 
Histological observations of 33 weeks old turkey also showed the presence of myoid cells. Myoid cells are cells located on the basement membrane of seminiferous tubules which are oval and flattened [22].

A 33 weeks old turkey has seminiferous tubules that are filled with dense mature spermatozoa. This is consistent with the statement of Rasyaf and Amrullah [8] that male turkeys that are sexually mature and can be used as breeds are 33 weeks old turkeys. The 33 weeks old turkey undergoes an end process spermatogenesis called spermiogenesis. This can be concluded from the appearance of spermatozoa in the seminiferous tubules. Spermiogenesis begins after the spermatids change from round spermatids to elongated spermatids [23]. According to Aire [20], when the spermatids change into spermatozoa, the Sertoli cells and Leydig cells begin to function.

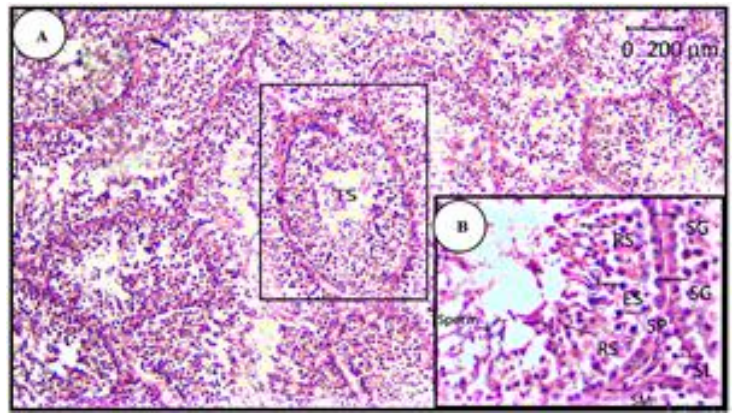

Figure 3 A 33-weeks turkey testicular microphotography. (A). The number of seminiferous tubules is large. The Seminiferous Tubule (TS) is already filled with spermatogenic cells and spermatozoa. (B). Inset A, showing the presence of Leydig (SL) cells; Sertoli cells (SC); Myoid cells (SM) on the basement membrane;
Spermatogonia (SG); Primary spermatocytes (SP); Round Spermatid (RS); Elongated Spermatid (ES); Spermatozoa (Sperm). HE staining. Scale: $200 \mu \mathrm{m}$ (A) and $30 \mu \mathrm{m}$ (B).

Based on the results of histological observations, it can be concluded that turkeys have different spermatogenesis phases for each age. According to Mahmood [24], age affects the histological structure of the testes. The testes at a young age usually only show Sertoli cells and a few spermatogonia in the tubules, while at adulthood, spermatogenesis activity will be seen, namely the presence of spermatogonia, primary spermatocytes, secondary spermatocytes, spermatids, and spermatozoa.

\subsection{Turkey Testicular Histomorphometry}

The results of histomorphometric measurements of turkey testes based on age levels including seminiferous tubule diameter, seminiferous tubule epithelial thickness, and seminiferous tubule lumen diameter are presented in Table 1.

The results of the analysis using ANOVA showed that there were significant differences $(\mathrm{P}<0.05)$ among the age groups in term of seminiferous tubule diameter, seminiferous tubular epithelial thickness, and seminiferous tubular lumen diameter. Follow-up results using the Duncan test showed that the seminiferous tubule diameter in the 12, 20 and 33 week age groups showed a significant difference $(\mathrm{P}<0.05)$. Sarma and Devi [25] stated that age has an effect on the increase in the diameter of the seminiferous tubules.

Table 1. Mean \pm SD of turkey testis histomorphometry by age level

\begin{tabular}{|c|c|c|c|}
\hline \multirow{2}{*}{ Size parameters $(\mu \mathrm{m})$} & \multicolumn{3}{|l|}{ Age group } \\
\hline & 12 weeks & 20 weeks & 33 weeks \\
\hline The diameter of the seminiferous tubules & $109.14 \pm 20.32 \mathrm{a}$ & $158.42 \pm 19.56 b$ & $203.00 \pm 40.08 \mathrm{c}$ \\
\hline The epithelial thickness of the seminiferous tubules & $18.00 \pm 3.60 \mathrm{a}$ & $43.00 \pm 6.85 b$ & $52.85 \pm 15.74 b$ \\
\hline The lumen diameter of the seminiferous tubule & $73.00 \pm 13.01 \mathrm{a}$ & $74.71 \pm 22.55 \mathrm{a}$ & $95.85 \pm 9.61 b$ \\
\hline
\end{tabular}

a, b, c differences superscript within the same row indicate significant differences $(\mathrm{P}<0.05)$.

The thickness of the seminiferous tubular epithelium, based on the follow-up results using the Duncan test showed that the 12 week age group was significantly different $(\mathrm{P}<0.05)$ compared to 20 week and 33 week age group, while the 20 week and 33 week age group showed not significant differences $(\mathrm{P}>0.05)$. Sertoli cells and spermatogenic cells are the constituent cells of the seminiferous tubule epithelium so that the thickness of the seminiferous tubule epithelium corresponds to the level of development of the cells [26]. The increasing the thickness of the seminiferous tubule epithelium, the more spermatozoa formation process develops [27].
The lumen diameter of seminiferous tubules in 33 week age group showed a significant difference $(\mathrm{P}<0.05)$ compares to the 12 week and 20 week age group, but the 12 week age group showed no significant difference compared with the 20 weeks age group $(\mathrm{P}>0.05)$. Okpe and Ezeasor [28] stated that the wider the diameter of the seminiferous tubule lumen, the more spermatozoa produced.

Based on the results of histomorphometric observations of the turkey testes, it can be concluded that age has an effect on the increase in the size of the seminiferous tubules. White et al. [29] stated that the increasing age factor has an effect on the increase in the 
size of the seminiferous tubule diameter, the thickness of the seminiferous tubule epithelium, and the seminiferous tubule lumen diameter.

\section{CONCLUSION}

Based on the results of histological and histomorphometric observations of turkey testes with different ages, it was concluded that there were different spermatogenesis phases that were different for each age, namely the spermatocytogenesis phase in 12 weeks of age turkey, myogenesis phase in turkeys aged 20 weeks, and the spermiogenesis phase in turkeys aged 33 weeks. The development of the spermatogenesis phase at each age of turkey causes the seminiferous tubule diameter, seminiferous tubule epithelial thickness and seminiferous tubule lumen diameter to increase.

\section{AUTHORS' CONTRIBUTIONS}

All authors equally contributed to the preparation and editing of the manuscript.

\section{ACKNOWLEDGMENTS}

The authors gratefully acknowledge the Faculty of Veterinary Medicine, Universitas Syiah Kuala for the facility provided.

\section{REFERENCES}

[1] D.G. Becker, Atlas of Aves and Vertebrates. (Translated by: Rosana Hariyanti), Tiga Serangkai Pustaka Mandiri, Solo, 2006.

[2] B.D. Murphy, Research in animal reproduction: quo vadimus, Anim. Reprod. 9(3) (2012) 217-222.

[3] S. Wahyuni, B. Anggara, M. Akmal, M. Hamny, M. Sabri, The pattern of distribution of carbohydrates in the male sexual accessory glands (Muntiacus muntjak muntjak), J. Vet. Med. 8(2) (2014) 141-146.

[4] M.S. Yahaya, A.L. Nwannenna, S.T. Fadason, P.I. Rekwot, Testicular morphometry and sperm reserves of local turkey toms fed varying levels of protein in diet, Sokoto J. Vet. Sci., 15(3) (2017) 10-14.

[5] L. Wei, K.M. Peng, H. Liu, H. Song, Y. Wang, L. Tang, Histological examination of testicular cell development and apoptosis in the ostrich chick, Turk J. Vet. Anim. Sci. 35(1) (2011) 7-14.

[6] D.M. Kelly, T.H. Jones, Testosterone: a metabolic hormone in health and disease. Soc. Endocrinol. 217(3) (2013) 25-45.

[7] S.I.A., Elbajory, M.D.E. Tingari, M.A. Abdalla, Morphological study of the testis of adult Sudanese duck (Anas platyrhinchos). Int. J. Anim. Vet. Adv. 5(3) (2013) 103-107.
[8] M. Rasyaf, I.K. Amrullah, Breeding Turkey. Selfhelp spreader, Jakarta, 1983.

[9] V. Gerzilov, A. Bochukov, G. Penchev, P. Petrov, Morphological and histological features of testes in landes ganders. Sixth Int. Sci. Agric. Symp. 6 (2015) 1782-1787.

[10] W. Federer, experimental design, theory, and application. Mac. Milan, New York, 1963.

[11] J.A. Kiernan, Histological and histochemical method: Theory and practice. 2nd Edition. Pengamon Press, New York, 1990.

[12] V.P. Eroschenko, DiFiore histology atlas with functional correlation. 12th edition. EGC, Jakarta, 2015.

[13] H. Rodriguez, E. Navarro, L. Sarabia, C. Tamayo, M. Sepulveda, J. Inostroza, J.C. Araya, K. Moriguchi, Histological and functional organization in human testicle: expression of receptors c-kit and androgens, Int. J. Morphol, 26(3) (2008) 603-608.

[14] G.R. Vazquez, R.H.D. Cuna, F.J. Meijide, G.A. Guerrero, Spermatogenesis and changes in testicular structure during the reproductive cycle in Cichlasoma dimerus (Teleostei perciformes), Acta Zoologica 93(2011) 338-350.

[15] M.D. Griswold, Spermatogenesis: the commitment to meiosis, Physiol. Rev. 96 (2016) 1-17.

[16] C. Landim, F.C. Abdalla, C.M.A. Hofling, Morphological changes of Sertoli cells during the male reproductive cycle of the teleost Piaracatus mesopotamicus, Brazil. J. Biol. 65(2) (2005) 1-8.

[17] L. Johnson, D.L.J. Thompson, D.D. Varner, Role of Sertoli cell number and function on regulation of spermatogenesis. Anim. Reprod. Science, 105(2008) 23-51.

[18] D.D. Mruk, C.Y. Cheng, Sertoli-Sertoli and Sertoligerm cell interactions and their significance in germ cell movement in the seminiferous epithelium during spermatogenesis, Endocrine Rev. 25(5) (2004) 747 806.

[19] K.J. Teerds, I.T. Huhtaniemi, Morphological and functional maturation of Leydig cells: from rodent models to primates, Human Reprod. Update 21(3) (2015) 310-328.

[20] T.A. Aire, Spermiogenesis in birds. Spermatogenesis 4(3) (2014) 1-36.

[21] H.C. Dreef, V.E. Esch, D. Rijk, Spermatogenesis in cynomolgus monkey (Macaca fascicularis): a practical guide for routine morphological staging, Toxicol. Pathol. 35(2007) 395-404. 
[22] D. Fernandez, M.V. Bertoldi, L. Gomez, A. Morales, E. Callegari, A. Lopez, Identification and characterization of myosin from rat testicular peritubular myoid cell, Biol. Reprod. 79(2008) 12101218.

[23] C.Y. Cheng, D.D Mruk, Regulation of spermiogenesis, spermiation and blood-testis barrier dynamics: novel insight from studies on Eps8 and Arp3. Biochem. J. 435 (2011) 553-562.

[24] I.M. Mahmood, Histological changes in testicular tissue with age, Tikrit J. Pure Sci. 13 (3) (2008) 1-7.

[25] K. Sarma, J. Devi, Morphometrical changes of the seminiferous tubules and leydig cells in assam goats (Capra hircus) from birth to 10 months. J. Appl. Anim. Res. 45(1) (2017) 268-274.

[26] F.F.L. Almeida, M.C. Leal, L.R. Franca, Testis morphometry, duration of spermatogenesis, and spermatogenic efficiency in the wild boar (Sus scrofa scrofa), Biol. Reprod. 75(2006) 792-799.
[27] M.T. Balarini, T.A.R.D. Paula, S.L.P.D. Matta, J.V. Peixoto, F.L.G. Leite, R. Junior, A.C.C. Junior, N.J. Walker, Stages and duration of the cycle of the seminiferous epithelium in oncilla (Leopardus tigrinus). Theriogenology 77 (2012) 873-880.

[28] G.C. Okpe, D.N. Ezeasor, Influence of naturally unilateral cryptorchidism on the histomorphometry of the testes and daily sperm production in West African dwarf goats. Iran. J. Vet. Res. 17(1) (2016) 13-19.

[29] D. White, J.G. Berardinelli, K.E. Aune, Age variation in gross and histological characteristics of the testis and epididymis in grizzly bears. Ursus 16(2) (2005) 190-197. 